\title{
JOHN MILLINGTON SYNGE'S RIDERS TO THE SEA A PRAGMATIC ANALYSIS Noha Hussain Abd El-Fatah
}

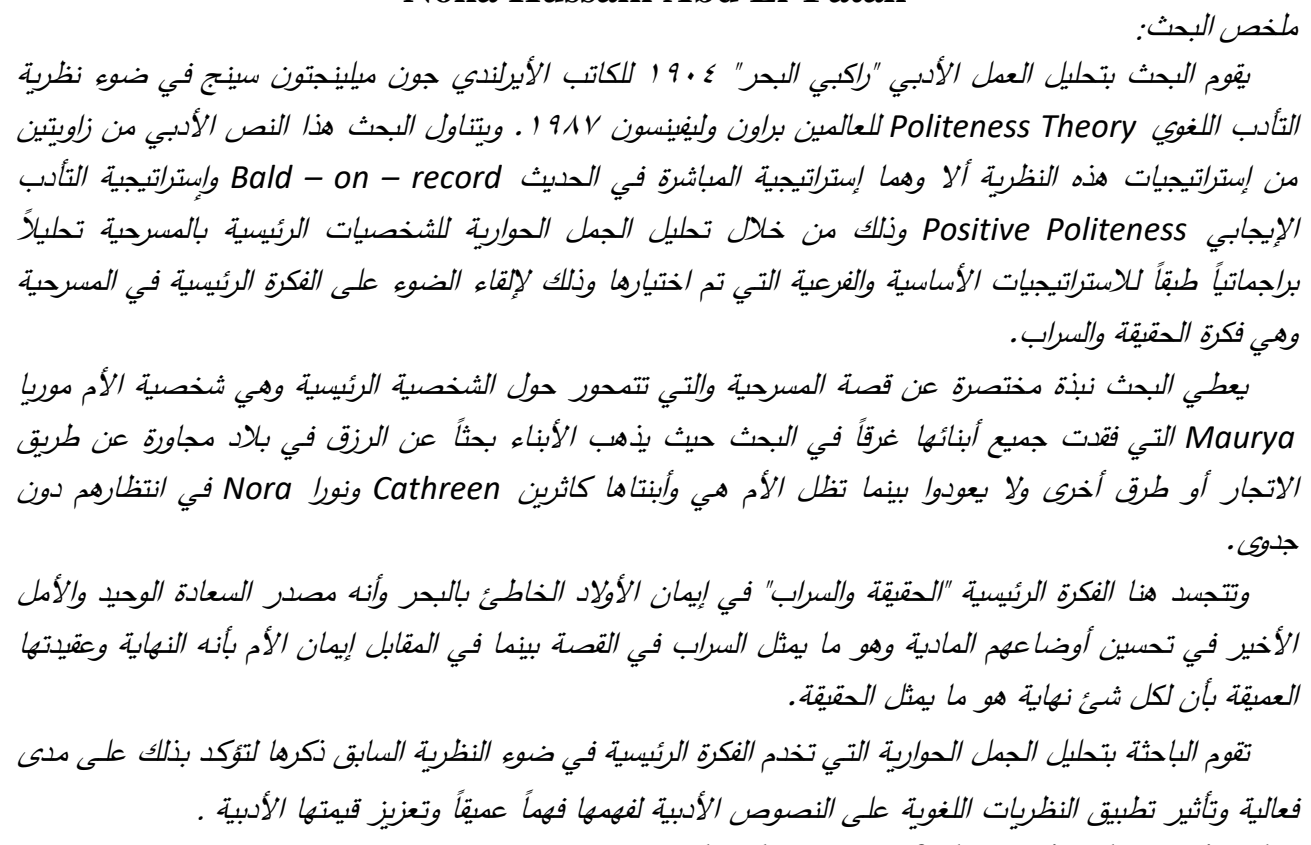

\section{Introduction:}

This research deals with the analysis of the literary text in the light of the Brown \& Levinson's (987) Theory of Politeness. It identifies the FTAS (Onrecord and Positive Politeness strategies) which structure the discourse of Synge's play Riders to the Sea (1904). It also investigates their role in the interpretation of the characters' speech situations which are mainly used to highlight the main theme in play.

Politeness strategies in Riders to The Sea:

The research deals with the pragmatic analysis of the main theme of the play, namely the theme of appearance and reality, in Synge's Riders to The Sea (hence after $R S$ ). It deals with the dialogues of the main characters in the play; Maurya (Maur) the old mother, her two daughters: Cathleen(Cath) and Nora, and her son Bartley(Bart) as speech situations in order to trace the development of the main theme in the play.

The analysis focuses mainly on analyzing the politeness strategies used by each character in relation to the main character-Maur- throughout the three stages of the play. The aim of this is to present a sufficient analysis of MaurChildren relationship in terms of Brown and Levinson's (1987) major politeness strategies Bald - on record (BOR) and Positive Politeness (PP) and their substrategies.

Before getting to the analysis of Maur-Children conversations, one has to begin with a brief account of Maur's story, which functions as the background knowledge (the context) for the selected speech situations under investigation in this section.

Maurya, the old mother, is the central character in Synge's play Riders to the Sea, the mother who sacrifices her husband and her sons to the sea because, 
for her, the sea symbolizes eternity. Although she believes deeply in the idea, Maur tries to stop her last son Bart from sailing to Connemara to sell the two horses they own at the Galway fair, but the son insists on going.

Bart goes against Maur's will and as a result she refuses to give him her blessing. Maur sees a vision of her drowned son Michael sitting upon the grey pony which she considers a message from Heaven for her as a sign of Bart 's death. Here, as Abousenna, (2010) argues "realism is used as a means to confirm myth. The real reason is seen in the light of the unreal, magic of the myth.

After the sea takes her last man, Maur feels "great rest" $(R S: 13)$. It is just her satisfaction with fate that gives her more strength. Her heroism as Ronan (2002) suggests lies mainly in her ability to accept her destiny.

-Bald-on-record politeness strategy in Maur-Children relationship:

This section deals with the use of the Bald-on-record politeness strategy (BOR) in Maur-Children relationship. Table (1) gives the frequency distribution of this strategy during the three stages of the play in Maur-Children conversations:

Table(1):Bald-on-record distribution in Maur-Children conversations during the three stages of $R S$.

\begin{tabular}{|l|c|c|}
\hline $\begin{array}{c}\text { Bald-on- } \\
\text { record } \\
\text { strategy }\end{array}$ & Maur & Children \\
\hline First stage & 11 & 11 \\
\hline Second stage & 4 & 20 \\
\hline Third stage & 10 & 2 \\
\hline \multicolumn{2}{|c|}{ The frequencies of the BOR }
\end{tabular}
strategy given in table (1) show that the BOR strategy is to some degree equally used by both Maur on one hand and her Children on the other hand but with different motives.

Maur's domineering attitude towards her children, Bart and the two daughters Cath and Nora comes from her fear of losing her last man Bart. Such a threatening and authoritarian attitude Maur has towards her Children leads them to stand in her face and defend their dream of leading a better life. It is a battle of words the characters are engaging in especially in the first stage. The old mother is trying to stop her son from riding the sea and the son insists on leaving the village in order that he can sell the horses and gain money.

In the play, the theme of illusion and reality has many faces. The contrast between the villagers' acceptance and satisfaction with fate 'reconciliation to God's will' and viewing the sea as Holly water that gives them safety is one facet of the theme of illusion and reality. The sea, itself, is the symbol of both reality and illusion and at the same time, it is the symbol of life and death.

This concept is quite clear from the first situation of the first stage in MaurChildren relationship till the end of the play. In the following extract, Maur is using the BOR strategy while talking about Bart with her young daughter Nora:

(1) Maur (sitting down on a stool at the fire) :He won't go this day with the wind rising from the South and West. He won't go this day for the Young Priest will stop him, surely.

(2) Nora: He'll not stop him, mother, and I heard Eamon Simon and Stephen Pheety and Colum Shawn saying he would go.(RS: 4$)$.

In (1), Maur's use of the BOR negative statement ('he won't go this day') (4) functions as a direct threat to Nora's positive and negative faces. She tries to exercise power over her daughter to give her a sympathetic advice or warning from the sea ('the wind is rising from the South and the West')(4).

In response to her mother's BOR language, Nora uses the BOR tactic to declare a direct fact to her poor mother adopting the same negative particle "not" : ('he will not stop him')(4) to tell her 
mother that she cannot have power over Bart who already decides to ride the sea.

The following utterance (3) shows that Maur's use of the direct BOR question throughout this interaction represents a constant source of threat especially a spiritual one for her daughter who realizes her mother's fear and responds positively to it :

(3) Maur: Where is he itself?

(4) Nora :He went down to see would there be another boat sailing in the week and I'm thinking it won't be long till he's here now...(RS: 5).

In relation to her son Bart, Maur seldom uses the redressive types of politeness strategies because her discourse with him belongs to the first case of the BOR strategy ' Cases where threat to H's face is small' where performing the FTA is in the H's interest/ benefit. She uses the BOR question not to direct a threat to his face but to give him warning from danger.

So, the investigation of MaurBart relationship in this stage is roughly restricted to this analysis of the sample of their BOR utterances:

(5)Maur: You'd right to leave that rope, Bartley, hanging by the boards (Bartley takes the rope). It will be wanting in this place, I'm telling you, if Michael is washed up tomorrow morning, or the next morning, or any morning in the week; for it's a deep grave you'll make him, by the grace of God. (RS:5).

Here, in (5), Maur goes on her use of the BOR warning technique to attract Bart's attention to the importance of staying in the house in order to wait his brother's dead body and make him a good funeral.

Similarly, in the following utterance Bart uses the BOR strategy in order to deliver a direct message to his mother reflecting his absolute refusal to her command. There is no way for Bart to obey his mother and miss the fair where he can sell the two horses.

(6)Bart (beginning to work with the rope):I've no halter the way I can ride down the mare, and $I$ must go now quickly. This is the one boat going for two weeks or beyond it, and the fair will be a good fair for horses, I heard them saying below. (RS:5).

Again, the BOR usage in this case, utterance (7), follow what Brown and Levinson's (1987:98) argue that "doing the FTA is primarily in H's interest".

(7) Maur: It's a hard thing they'll be saying below if the body is washed up and there's no man in it to make the coffin,...

(8) Bart: How would it be washed up, and after looking each day for nine days, and a strong wind blowing a while back from the west and south? (RS:5).

In (7), Maur attempts to convince Bart to stay on the island using the BOR command which hides a meaning of threat and warning at the same time. She wants to save his life as well as to worship the customs of the island which demand Bart to wait for the arrival of his brother's (Michael's) body to dig a grave for him. Bart, on the other hand, resorts to the BOR strategy in directing the rude question to his mother in utterance (8) which shows his disinterest in this conception of customs.

In the following extract, Maur asks Bart a BOR question with no mitigation. She also uses the BOR statement to warn him about the impeding danger because in this urgency case efficiency is more important than mitigation:

(9) Maur: If it isn't found itself, the wind is raising the sea, and there was a star up against the moon, and it rising in the night. If it was a 


\begin{tabular}{|c|c|}
\hline $\begin{array}{l}\text { to } \\
\text { he } \\
\text { his } \\
\text { yic } \\
\text { all } \\
\text { he } \\
\text { wn } \\
\text { ms } \\
\text { ee }\end{array}$ & $\begin{array}{l}\text { their extensive use of the BOR language in } \\
\text { their questions and harsh linguistic } \\
\text { behavior. } \\
\text { The friction between Maur and } \\
\text { her son reaches its maximum level when } \\
\text { he violently refuses to respond to his } \\
\text { mother's commands. Maur increases the } \\
\text { rudeness of her command by addressing } \\
\text { Bart ('a hard and cruel man')(6). She } \\
\text { draws on the impolite use of the BOR } \\
\text { strategy because, according to Brown and } \\
\text { Levinson's (1987) second case of BOR } \\
\text { usage, she wants to be rude because she } \\
\text { does not fear retaliation from her } \\
\text { interlocutor Bart. } \\
\text { (12) Bart (getting his purse and tobacco): } \\
\text { I'll have half an hour to go down, } \\
\text { and I'll see me coming again in two } \\
\text { days, or in three days, or maybe in } \\
\text { four days if the wind is bad. (RS:6). } \\
\text { Bart's direct BOR declaration to } \\
\text { question in response to her mother's BOR } \\
\text { harsh address form ('cruel man')(6).She } \\
\text { Maur that he will go to the fair is another } \\
\text { facet of illusion because he is sure that he } \\
\text { will be back in two or more day's. } \\
\text { Throughout the play, there is a } \\
\text { (14) Cath: It's the life of a young man to } \\
\text { be going on the sea, and who would } \\
\text { listen to an old woman with one } \\
\text { daughter Cath. This is apparent in Cath's } \\
\text { resistance to her brother's staying home. } \\
\text { She sided with Bart against her mother's } \\
\text { old beliefs. Cath blames her mother for } \\
\text { making troubles into the house ('there is } \\
\text { no sense left on any person in a house } \\
\text { where an old woman would be talking } \\
\text { forever')(7).Cath depends heavily on the } \\
\text { BOR language in expressing her objection } \\
\text { to her mother's beliefs: } \\
\text { (13) Maur (turning round to the fire, and } \\
\text { putting her shawl over her head): } \\
\text { Isn't it a hard and cruel man won't } \\
\text { hear a word from an old woman, } \\
\text { the she hoolding him from the sea? }\end{array}$ \\
\hline
\end{tabular}


accompanied this with the impolite address form ('an old woman')(6) which functions as an insult used to damage Maur's face, and the result is simply Bart's departure:

(15)Bart (taking the halter) : I must go now quickly. I'll ride down on the red mare, and the grey pony'll run behind me.... The blessing of God on you. He goes out.(RS:6).

Bart's use of the BOR declaration of his departure is direct without any mitigation. He sees that this act is in the benefit of the whole family and this is the only way to achieve his dreams so, he does not care a bit for saving his audience's face.

The absence of smile is apparent in the dialogue of the characters and no decoration is found in their language. Obliviously, all the characters in the three stages of the play exercise the use of the BOR strategy for different reasons rather than power. Some of the selected extracts under examination, which include the use of the BOR tactic, belong to 'Cases of urgency or emergency', while others belong to 'Cases where the threat of FTA is small' because the utterance is in the H's benefit or interest.

In the following speech situation, Cath's adoption of the BOR strategy is the result of her power over her mother in this particular situation. This power is the power which is taken from being the younger and the more powerful than her mother the older and the weaker participant. Cath, here, wants to be rude and does not even care for maintaining her mother's face by blaming her severely using the rude BOR question:

(16) Cath: Why wouldn't you give him your blessing and he looking round in the door? Isn't it sorrow enough is on everyone in this house without you sending him out with an unlucky word behind him, and a hard word in his ear?(RS:6-7)
Cath, in (18), continues using the impolite rude language while talking to her sister Nora about their mother who insists on not giving her blessings to Bart before his departure. She increases the threat of the FTA through addressing her mother with the impolite address form ('old woman')(7).

(17) Nora: And it's destroyed he'll be going till dark night, and he after eating nothing since the sun went up.

(18) Cath (turning the cake out of the oven) : It's destroyed he'll be, surely. There's no sense left on any person in a house where an old woman will be talking forever. $(R S: 7)$

Again, the theme of illusion and reality is embodied in Cath's total belief in the glory of her mother's blessing. Maur's power over her children is reflected in this situation. The importance of her blessing in the hearts of the children is quite clear. Her power lies not only in domineering the cottage customs but also in domineering the village customs. Here, as Ronan (2002) suggests, "the strange identification between the two opposites (reality and appearance), always subtly evident in Synge's work"(52).Synge produces another facet of illusion; that Maur's children believe that without her blessings or even words of hope, Bart will meet his end. In the Irish custom, the absence of the mother's blessings will definitely lead to bad fate. Cath, the older daughter, who is sharp-tongued as her mother and who often opposes her continues relying heavily on the BOR language while asking her mother to go and give her blessings to her brother Bart. In (19), Cath gives her mother the BOR orders using the imperative forms of the verbs('let') and ('go now')(7) which are really threatening to Maur's face:

(19) Cath (cutting off some of the bread and rolling it in cloth; to Maur): Let you go down now to the spring well and give him this and he passing. 
You'll see him then and the dark word will be broken, and you can say 'God speed you' the way he'll be easy in his mind.

(20) Maur(taking the bread):Will I be in it as soon as himself?

(21) Cath: If you go now quickly?

(22) Maur (standing up unsteadily) : It's hard set I am to walk.(RS:7).

Maur is certain that her son will die, she knows that her blessing words can never stop that. Here, she is so strong to face reality with all its harshness when she refuses once to give her kind word to Bart because she feels that it is a lie, and on the other time the words are chocked in her throat for the same reason. Maur is absolutely aware that her blessing will not make any difference.

The following utterance marks the end of the first stage of Maur-Children relationship. The end of the struggle between appearance and reality:

(23) Maur (taking a stick Nora gives her):

In the big world the old people do be leaving things after them for their sons and children, but in this place it is the young men do be leaving things for that do be old.(RS:7)

In this last situation of the first stage of Maur - Children relationship, Maur uses the BOR language to declare a fact, a reality and to show her total reconciliation to God's will.

In the second stage, truth is in its way to be revealed. The two daughters Cath and Nora just receive their brother's (Michael's) clothes. They are trying by all means possible to hide reality from their broken hearted mother. We see Maur's children trying to protect her, fear her authority and anger, and worry about her response to the news of Michael's death.

The following extracts are loaded with the two daughters' use of the interrogatives and imperatives which bear a positively-polite interpretation of their love and respect to their poor mother's feelings and which belong to the ('Cases of urgency or emergency') rather than 'power' or 'rudeness'.

After Maur goes to give Bart her blessings, the two daughters begin to open their dead brother's bundle:

(24) Cath: Wait, Nora, maybe she'd turn back quickly. She's that sorry, God help her, you wouldn't know the thing she'd do.

(25) Nora: Is she gone round by the bush?

(26) Cath (looking out): She's gone now. Throw it down quickly, for the Lord knows when she'll be out of it again. (RS:7).

In (24) and (26), Cath gives Nora two BOR orders, using the imperative form of the verb, which are not threatening to H's (Nora's) face since they belong to ('Cases of urgency/ emergency') before their mother returns back to the house. Nora's BOR direct and rapid question to Cath is used for the same reason.

Both Cath and Nora try, on purpose, to hide reality from their poor mother, but in the following situation they escape from it through believing in the Young Priest's illusive words. Illusion can be found not only in the two daughters' view, but also in the islanders' view of God who cannot, as the Young Priest once claims, save Bart's soul simply because the sea is stronger than His own will: ('it's the little the like of him knows the sea')(11) says Maur about him as he promises her that God won't leave her without no living son.

It is not illusion, it is delusion the villagers have that there is a force over which God has no control. It is the force of the sea, the single dominant force in their lives:

(27) Nora( getting the bundle from the loft): The Young Priest said he'd be passing to-morrow, and we might 
go down and speak to him below if it's Michael's they are surely.

(28) Cath(talking the bundle): Did he say what way they were found? $(R S: 8)$.

Cath's tendency to evade reality and escapes into illusion appears in the following situation when she tries to fly from the truth after seeing her drowned brother's clothes. Here reality and illusion are mingled together when she refuses, at the beginning, to face fate:

(29) Cath : It's the same stuff, Nora; but if it is itself, aren't there great rolls of it in the shops of Galway, and isn't it many another man they have a shirt of it as well as Michael himself?

(30) Nora(who has taken up the stocking and counted the stitches, crying out): It's Michael Cathleen, it's Michael ; God spare his soul, and what will herself say when she hears this story, and Bart on the sea?(RS:9)

Cath, in (29), resorts to the direct use of the BOR question which does not function as a threat to Nora's face. The BOR interrogative is softened by the negative particle ('not') which shows that Cath loses touch with reality as a result of this great chock. In her flight from reality, she denies that the stuff is of her brother: ('isn't it many another man they have a shirt of it as well as Michael himself')(9) until Nora makes the BOR declaration of the truth that they are his. In doing so, she uses the same BOR strategy of questioning as a sign of sorrow.

Illusion cannot now be mistaken for reality and the characters have no other choice except meeting their harsh destiny. The following speech situations take another turn and both Cath and Nora are living the bitter experience not for the first time. They exchange BOR interrogatives exposing their deep sorrow:

(31) Cath (count the stitches): It is that number is it. (crying out) Ah, Nora, isn't a bitter thing to think of him floating that way to the far north, and no one to keen him but the black hags that do be flying on the sea?

(32) Nora(swinging herself half-round, and throwing her arms on the clothes): And isn't it a pitiful thing when there is nothing left of a man who was a great rower and fisher but a bit of an old shirt and plain stocking?(RS:9)

They are trying to escape from reality but in vain. It is fate and no one can escape from it at all:

(33)Cath: Put these things away before she'll come in. Maybe it's easier she'll be after giving her blessing to Bartley, and we won't let on we've heard anything the time he's on the sea.

(34) Nora (helping Cathy to close the bundle): We'll put them here in the corner.

They put them into a hole in the chimney corner. Cathleen goes back to the spinning wheel.

(35) Nora: Will she see it was crying I was?

(36) Cath: Keep your back to the door the way the light will not be on you. Nora sits down at the chimney, with her back to the door.(RS:9)

Obviously, in (33), (35), and (36) both Cath and Nora in this particular stage resort to the use of the BOR strategy through their recurrent use of imperatives and interrogatives. The use of the BOR tactic here is in the interest/benefit of the participants themselves. They are much interested in covering the truth from their mother. The extensive use of such BOR devices, ('put these things away'), ('will she (their mother) see..?') and ('keep your back..')(9), is a sign of their love and affection towards Maur. The BOR technique, thus, serves in giving the utterance a polite senes because these 
imperative forms function as a piece of 'advice'.

In fact, Cath's and Nora's decision of unrevealing the truth to their mother is a good example of willed illusion. They are deceiving themselves: "like islanders, Synge prefers easy, mythical explanations and solutions which are unconscious means of maintaining the status quo which, for Synge, is the Irish-cultural identity." (Abousenna,2010: XV). The characters are in a bad need for creating their own mythical world, so that they can bear their life.

Maur,who refuses to give Bart her blessing because she wants to punish him for going against her will, is now lamenting his death. She comes back home and the cloth with bread is still in her hand. The old mother sees a vision of her son Bart riding a red mare and while she is trying to pray for him, she sees her other son Michael, not Bart, riding the red mare and wearing new clothes. This vision inspires Maur of not only Michael's but also Bart's death. Her prophetic vision of both sons makes her certain they are really dead before anyone else knows.

Again, the situation is another example of the conflict between reality and illusion. Maur escapes into selfdeception which costs her pain. Her grief about the loss of her sons leads her to imagine the whole vision which, in turn, promotes her daughters to rely heavily on the BOR strategy through the nonredressive questioning:

(37)Cath (after spinning for a moment) : You didn't give him his bit of bread?

Maurya begins to keen softly, without turning round.

(38) Cath: Did you see him riding down?

Maurya goes keening.

(39)Cath (a little impatiently) : God forgive you, isn't it a better thing to raise your voice and tell what you seen, than to be making

lamentation for a thing that's

done? Did you see Bartley, I'm saying to you?(RS:10).

Cath, the quick-tempered and sharp-tongued daughter, selects the Baldon-record FTA while directing many questions to her shocked mother simply because she wants to exercise power over weak Maur. She is now the more powerful participant who knows everything and controls the events. Cath's use of the nonredressive bald-on-record technique is not only because she intends to be rude and damage her mother's face, but also because she tries to release herself from facing the harsh fate by pretending that nothing has happened.

(40) Cath (as before) : did you see Bartley?

(41) Maur: I seen the fearful thing.

(42) Cath (coming to the fire) : What is it a lis you at All?

(43) Maur (speaking very slowly): I've seen the fearfulest thing any person has seen...(RS:10).

In (41) and (43), Maur's lack of power is reflected on her use of the BOR statement or declaration of what she sees. Here, she is not aware of her daughter's threat and tries nothing to lessen the amount of it. The mother cannot feel nothing but grief.

On her attempt to show immense power over Maur, Cath hides sorrow and fear to her mother's scornful state. She tries the same trick of mistaking illusion for reality and deceives her mother all with the help of her sister Nora. They are both drawing on the BOR device directing questions and giving orders to their mother:

(44) Nora: Tell us what is it you seen.

(45) Maur: I went down to the spring well, and I stood there saying a prayer to myself. Then Bartley came along and he riding on the 
red mare ...,the son of God spare us, Nora!

(46) Cath: What is it you seen?

(47) Maur: I seen Michael itself.(RS: 10).

The daughters' fake denial of reality in front of their mother does not make any sense. Maur tells her vision as if she recalls a real story from the memory and Nora uses the BOR question to fly from reality,in (48). Maur follows the same tactic through her unexpected declaration of her false belief in the power of the sea over the power of God. Again, it is delusion which dominates the minds and spirits of all the peasants in the village:

(48)Nora: Didn't the Young Priest say Almighty God won't leave her destitute with no son living?

(49) Maur( in a low voice, but clearly) It's little the like of him knows of the sea.....(RS: 11).

As the action proceeds, Cath refuses to depart herself from her willed illusive world. It is the harshness of reality that makes her drown into fantasy. Cath knows very well that her mother's feeling is right, but she does not want to either declare reality or even confess it to herself. In fact, she lies to herself.

On the other hand, Maur begins to be so carried by fantasy that she becomes detached from reality. In doing so, both Cath and her mother challenge each other in using the direct BOR language through questions as seen in the following utterances (50) and (51):

(50) Cath: Michael is after being found in the far north, and when he is found there how could he be here in this place?

(51) Maur:There does be a power of young man floating round in the sea, and what way would they know if it was Michael they had, or another man like him...(RS: 12).
Cath does not have enough strength to face fate now, but when she realizes that there is no way to escape from accepting destiny, she decides to reconcile with the truth and not to go on in her myth. The following direct BOR declaration reflects this:

(52) Cath: It's Michael, God spare him, for they're after sending us a bit of his clothes from the far north.

She reaches out and hands Maurya the clothes that belong to Michael. Maurya stands up slowly, and takes them in her hands. Nora looks out. (RS: 12).

Meanwhile, the climax reaches its peak with the great shock of losing both Michael and Bartley at the same time. Although Maur and her daughters are suffering from their harsh conditions, they all have to accept the cruelty of fate:

(53) Nora: They're carrying a thing among them, and there's water dripping out of it and leaving a track by the big stones.

(54) Cath (in a whisper to the woman who have come in): Is it Bartley it is ?

(55) One of the women: It is, surely,God rest his soul.(RS: 12).

Maur's prophetic story becomes true now. She is describing how the body of one of her sons is carried in, while the door opens and her story is repeated with all its details with the body of Bartley drowned. Maur, here, is totally aware of the dark sides of life and death.

In the third stage of MaurChildren relationship, the BOR strategy usage is quite rare because the nature of the relationship changes. The BOR strategy is used here for different reasons and with different interpretations. One of the main reasons is the characters' tendency to expose their inner feelings bluntly without decoration. The calm tempo of the third stage of this relationship lies in their satisfaction with hard fate. 
As seen in table (1), the BOR strategy usage is dominated by Maur who is the power-holder in this crucial stage. It is the power of faith, the power of getting rid of illusion and meeting reality. Although she is lamenting her sons, she gains more power from their death. Hill, P.G. argues that "Maurya's faith may not be shaken, but it is a harsh, unbending faith that, like the sea, has little about it of forgiveness or mercy." (International Journal of social science and humanity, Vol.1., No.4. November 2011).The poor mother is getting stronger now.

On the contrary, the BOR strategy is rarely found in the two daughters' utterances simply because they do not much take part in this hard scene and because they act as audience to their mother's scornful condition. In fact, they do not enjoy the power of faith as their mother does.

(56) Cath (to the women as they are doing so): What way was he drowned?

(57) One of the women: The grey pony knocked him over into the sea, and he was washed out where there is a great surf on the white rocks. (RS: 13).

Cath's BOR question in (56) bears her deep feeling of sorrow for her brother's death. She wants to get more details about how he met his end.

In the following speech situations, the BOR technique is used to reveal the truth beyond their acceptance to their destiny. The tragic mood is expressed through Maur's words which reflect her total awareness of the value of life as well as the dignity of death. Thus, the BOR language Maur uses in the third stage is not at all functioning as a threat to her audience:

Maurya has gone over and knelt down at the head of the table. women are keening softly

...Cath and Nora kneel at the end of the table...
(58) Maur (raising her head and speaking as if she didn't see the people around her): They're all gone now, and there isn't anything more the sea can do to me... I'll have no call now to be up crying and praying when the windbreaks ... Give me the Holly water, Nora; there's small sup still on the dresser.

Nora gives it to her. (RS: 13).

Maur's use of the BOR imperative form of the verb in (58) ('give me the Holly water')(13) reflects not only her own culture, but also the culture of the primitive Irish islanders to worship the sea water. Although Maur manages to face fate, she is a traditional island woman with rural illusive concepts of seeing the sea as Holly water. It is another facet of illusion which Maur and all other islanders can never live without. Through asking Nora to give her the 'Holly water' to put on Bart's dead body, Maur is giving him her blessing but this time she is following and respecting the island's ceremonial customs.

Depending heavily on the BOR strategy, Maur in (59) uses the direct language to expose her faith in front of everybody:

(59) Maur (drops Michael's clothes across Bartley's feet, and sprinkles the Holly water over him) : It isn't that I haven't prayed for you, to the Almighty God. It isn't that I haven't said prayers in the dark night till you wouldn't know what I'd be saying; but it's a great rest I'll have now, and it's time, surely. It's a great rest I'll have now, and great sleeping in the long nights after Samhain, if it's only a bit of wet flour we do have to eat, and maybe a fish that would be stinking.

She kneels down again, crossing herself, and 
saying prayers under her
breath.( RS:13).
Maur's BOR linguistic behavior in (58) shows her regret for not giving her blessing to Bart before leaving the island. In fact, she does not care about impingement because in such a cruel situation, she exercises power over her guilty self. At the end of the situation, she regains her strength and becomes satisfied with the truth of death as Hill says :"Maurya's fundamental faith seems not to be shaken by the loss of her last two sons and she believes that the Young Priest; the community's spiritual leader, knows a little about the sea."(2011). Now, Maur is ready to go on in her life without being afraid of losing anything.

In the following extract, Cath tries to share her mother the same sense of satisfaction as she surrenders to God's will using the following BOR declaration:

(60) Cath (to an old woman) : Maybe yourself and Eamon would make a coffin when the sun rises. We have fine white boards herself bought, God help her, thinking Michael would be found, and I have a new cake you can eat while you'll be working. (RS: 13-14).

The two following speech situations show that Maur's lament is not only for her family, but also for all riders to the sea, and after all, she has to reconcile to God's choice.

(61) Maur (puts the empty cup mouth downwards on the table, and lays her hands together on Bartley's feet) : They're all together this time, and the end is come. May the Almighty God have mercy on Bartley's soul, and on Michael's soul, and on the souls of Sheamus and Patch, and Stephen and Shawn (bending her head); and may He have mercy on my soul, Nora, and on the soul of everyone is left living in the world.( RS: 14).
Maur goes on saying:

(62) Maur (continuing) : Michael has a clean burial in the far north, by the grace of the Almighty God. Bartley will have a fine coffin of the white boards, and a deep grave surely. What more can we want than that? No man at all can be living for ever, and we must be satisfied.

She kneels down again and the curtain falls slowly.(RS: 14).

In (62), Maur adopts the BOR strategy through welcoming death instead of revolving against it. This usage belongs mainly to ('Cases of FTA-oriented BOR') where mitigation is not required because the BOR act is 'oriented to face': ('what more can we want than that? No man at all can be living forever, and we must be satisfied')(14). The act then is directed towards the satisfaction with their own face: "By the end of the play, she (Maur) finds grace in that, with no more sons living, the sea can ask of God are a quick death and a clean burial" (Hill, 2011). The mother and the two daughters are trying to be gentle with themselves.

Conclusion

The present paper sheds the light on 'politeness' as a central concept in linguistic pragmatics. It focuses on Brown and Levinson's theory of politeness because it is considered the most accurate and comprehensive in the concepts of politeness. In other words, the outcome of Brown and Levinson's approach does not contradict the politeness principle of Grice, Lakoff's rules of politeness or Leech's politeness maxims. They are all derived from Brown and Levinson's theory of politeness.

Brown and Levinson's go further explaining Face Threatening Acts as any utterance that constitute a threat to face in one way or another. Doing FTA is part and parcel of language usage. If there were no FTAs, verbal interaction would become extremely odd and of no taste. No one 
would ever complain or ask another one to do something unless there was a FTA performed. Both authors propose four politeness strategies for performing FTAs:Bald-on-record, negative politeness, positive politeness and off-record.

The current research focuses on 'bald-on-record' and 'positive politeness' strategy's in the application of John Synge's play under discussion : Riders to the Sea. The reason is that these strategies are the most relevant and thus the most applicable to Synge's structure.

The analysis of data shows that the application of Brown and Levinson's (1987) model of linguistic politeness to these this play is an efficient toolkit for investigating the main theme of the play.

Findings relevant to Riders to the Sea: -Findings relevant to the bald-on-record strategy in Riders to the Sea:

The analysis of data shows that the bald-on-record strategy (BOR) plays an undeniable role in highlighting the main theme of Riders to the Sea; namely the theme of illusion and reality. The high frequencies of BOR strategy of almost all the major characters during the three stages of the play is a clear evidence of this concept.

Table (11) summarizes such high frequencies:

\begin{tabular}{|l|c|c|}
\hline Relationship & \multicolumn{2}{|c|}{ Maur-Children } \\
\hline Character/Stage & Maur & Children \\
\hline First stage & 11 & 11 \\
\hline Second stage & 4 & 20 \\
\hline Third stage & 10 & 2 \\
\hline Total & 25 & 33 \\
\hline
\end{tabular}

Table (2): Frequency distribution of the bald-on-record strategy in Synge's RS: A summary table.

The analysis concludes that there are different motivations behind the use of the BOR strategy. The dissertation is concerned with one factor behind these motivations: the 'relative power' $(\mathrm{P})$ of one participant over the other. As for the second and the third factors proposed by Brown and Levinson (1987)- social distance (D) and rank of imposition (R)they are excluded from the analysis since the first one,(D), is unsuitable for a mother-children relationship, and the second one , $(\mathrm{R})$, addresses the cultural aspects of politeness which is not the concern of the present study.

In the first stage of the play, there is an equal use of the BOR strategy from both participants: Maur on one hand and her children on the other hand. In fact, there is a strong connection between the first factor $(\mathrm{P})$ and their adoption of the BOR strategy. Maur's performed speech acts are characterized by a domineering attitude towards her children; Bart, Cath, and Nora. A threatening attitude which is, as a result, faced by a defensive one from the children in the face of their mother. Maur's children are trying to achieve their dreams of leading a better life, while their mother is trying with all what she has of effort to save their lives.

Therefore, according to Brown and Levinson (1987), BOR strategy usage in this first stage belongs to the first set of cases of non-minimizing of the face threat, i.e. "Cases of urgency or emergency" which is a main motivation of the use of the BOR strategy in Riders to The Sea in general. Such cases occurred in the three stages of the play where Maur exercises power over her children and they defend their right in gaining money and lead a better financial life. It is the power of fear and love that governed their relationship and makes the acts fall into the children's benefit.

In the second stage of MaurChildren relationship, the Children's use of the BOR tactic exceeds that of Maur's. We see her two daughters; Cath and Nora exchanging the direct BOR language not to exercise power over their mother but to show affection for her sometimes and to escape from reality other times. In such 
speech acts, BOR strategy is used because, as Brown and Levinson (1987: 96) suggest, "redress would actually decrease the communicated urgency", and also because "doing the FTA is primarily in H's benefit "(98).

In the final stage, Maur's adoption to the BOR strategy decreases to a great extent than that of her children. A stage where Maur resorts to the use of the BOR device because of her tendency to expose her piety bluntly without decoration. On the other hand, the children's use of such a tactic is quite rare because it is concerned with reflecting their affection and sorrow for their poor mother who lives a miserable state. It also belongs to cases where doing the FTA is in the H's interest or benefit.

To summarize, the BOR strategy is used in the dialogues of Riders to the Sea for three reasons. First, it is used because of a power differential between $S$ and $\mathrm{H}$, i.e. $\mathrm{S}$ is more powerful than $\mathrm{H}$ or the opposite, thus he/she paid little attention to the other's face and does not fear retaliation, but this happened in very few situations. Second, it is used because the speech acts performed are sometimes in $\mathrm{H}^{\prime} \mathrm{s}$ interest and for his/her benefit. Third, it is also used in many situations of urgency or emergency in which efficiency is more important than FTA mitigation.

In the last two cases, the use of BOR strategy results in polite speech acts sometimes despite their being performed directly without mitigation. This means that the use of BOR strategy can be used to perform polite as well as impolite speech acts. A conclusion which is supposed by both El-Shafey (1990) and Culpeper (2001b).
Bibliography

Abousenna, M. (2010)."Introduction to Riders to the Sea: The Playboy of the Western World and the Shadow of the Glen. Cairo: The Anglo. Egyptian Bookshop.

Culpeper, J. (1996). "Towards An Anatomy of Impoliteness." Journal of Pragmatics 25, 349367.

Culpeper, J. (2001). Language and Characterization: People in Plays and Other Texts. London: Longman.

Culpeper, J.(2000)."A Cognitive Approach to Characterization: Katherina in Shakespeare's The Taming of the Shrew." Language and Literature 9, 291-316.

El-Shafey, F.(1990). Politeness Strategies in Spoken British English and Spoken Egyptian Arabic: A contrastive Study. Unpublished doctoral dissertation , Cairo University , Egypt.

Hill, P.G. (1992). Our Dramatic Heritage: Classical Drama and the Early Renaissance, Fairleigh Dickinson. Oxford : Oxford University Press.

Ronan, M. (2002).Tragedy and Irish Literature:Synge, O'Casey, Beckett. Palgrave :Macmillan.

Wood, E.R. (1982). Riders to the Sea and The Playboy of the Western World, Great Britain, Fletcher and Son Ltd, Norwich. 